\title{
Life History of the Tamarind Weevil, Sitophilus linearis (Herbst) (Coleoptera: Curculionidae), on Tamarind Seed
}

\author{
James Adebayo Ojo ${ }^{1}$ and Adebayo Amos Omoloye ${ }^{2}$ \\ ${ }^{1}$ Department of Crop Production, Kwara State University, Malete 23431, Kwara State, Nigeria \\ ${ }^{2}$ Department of Crop Protection and Environmental Biology, University of Ibadan, Ibadan, Nigeria \\ Correspondence should be addressed to James Adebayo Ojo; jamesojo91@yahoo.com
}

Received 9 August 2015; Accepted 7 October 2015

Academic Editor: Francisco de Sousa Ramalho

Copyright (C) 2015 J. A. Ojo and A. A. Omoloye. This is an open access article distributed under the Creative Commons Attribution License, which permits unrestricted use, distribution, and reproduction in any medium, provided the original work is properly cited.

\begin{abstract}
The tamarind weevil, Sitophilus linearis Herbst (Coleoptera: Curculionidae), is an important pest of tamarind and other Caesalpinioideae. Investigating its life history is important in the implementation of management strategy. Its life history was monitored daily to understand its developmental biology on tamarind seed following standard procedures under laboratory conditions of $24-30^{\circ} \mathrm{C}$ temperature, $60-70 \%$ relative humidity, and $12 \mathrm{~L}: 12 \mathrm{D}$ photoperiod. The egg incubation period lasted 3.17 \pm 0.07 days. A mated female of S. linearis laid an average of $165 \pm 5.78$ eggs during an oviposition period of $86.8 \pm 2.47$ days. There were four larval instars, with a total larval developmental period of 16 days. The pupal period lasted 8 days, and adult lived $108.5 \pm$ 3.61 days. The overall growth ratio for the four instars was 1.33. There was a regular relationship and significant correlation $(r=0.94)$ between the stages of larval development and head capsule width.
\end{abstract}

\section{Introduction}

Tamarind (Tamarindus indica L.), apart from being an important tree crop, is also valued as fuelwood and ornamental [1], medicinal plant [2], and livestock feed [3]. Tamarind plants are very useful in a lot of ways, roots are useful with other native medicines for the treatment of leprosy and chest pain in Northern part of Nigeria [2], seeds are astringent for the treatment of dysentery, ulcer, boils, and diabetes [4], and the pulp and leaves are used for cooking, preparation of refreshing drinks, confections, and ice cream $[3,5]$, which necessitated man to explore different parts of tamarind for his use. While some insect pests like Paraplisa gularis, Corcyra cephalonica, and Caryedon serratus [6] are known to infest fruits and seeds in the field and store, tamarind weevil, Sitophilus linearis, is a true most devastating seed pest $[7,8]$, which is capable of causing economic damage to the seeds of this plant. S. linearis is a congeneric species of Sitophilus granarius (L.), Sitophilus oryzae (L.), and Sitophilus zeamais (Motsch.), important insect pests of stored products whose developmental activities and feeding could cause qualitative and quantitative damage $[9,10]$. The infestation of $S$. linearis begins from field after fruit ripening and damage continues when the fruits and seeds might have been harvested and stored. Life history of tamarind weevil was reported last in 1920 in United State of America [7]. Consequently, information on the developmental biology of this species is lacking in the literature in this part of the world as little or no documented work is available on it. Therefore, for effective management of the pest, it is pertinent to investigate the developmental biology of this pest in local environmental conditions due to its ability to attack Leguminosae. This study reports the biology of this pest on tamarind seed in Nigeria.

\section{Materials and Methods}

Tamarind fruits/seeds used were sampled from the total collections obtained from the field surveyed work on tamarind obtained from selected locations in the savannah areas of Nigeria, where tamarinds are predominantly available. This was done in the months of November to January 2012 and 2013. The seeds were carefully removed from pods and pulps; these clean seeds wrapped with cellophane paper were 
TABLE 1: Incubation, oviposition, longevity periods, and fecundity of $S$. linearis.

\begin{tabular}{lcc}
\hline Parameters & Mean \pm SE & Range \\
\hline Egg incubation period (days) & $3.17 \pm 0.07$ & $3-4$ \\
Oviposition period (days) & $86.8 \pm 2.47$ & $77-98$ \\
Fecundity & $165 \pm 5.78$ & $132-189$ \\
Adult longevity (days) & $108.5 \pm 3.61$ & $91-126$ \\
\hline
\end{tabular}

carefully stored inside deep freezer for two weeks to kill incipient infestation. They were removed from refrigerator, sorted, and left open under controlled environment in the laboratory to acclimatize before use, and their moisture content was determined to be $17.35 \%$.

Adults of Sitophilus linearis were collected from tamarind plants during the survey work to establish a culture in the laboratory. The culture of $S$. linearis was established in the Entomology Research Laboratory, Department of Crop Protection and Environmental Biology, University of Ibadan, Ibadan, under ambient temperature of $24-30^{\circ} \mathrm{C}, 60-70 \%$ relative humidity, and $12 \mathrm{~L}: 12 \mathrm{D}$ photoperiod. Twenty-five pairs of one-week-old tamarind weevil were introduced into $100 \mathrm{~g}$ seeds of tamarind in $10 \mathrm{lb}$ capacity Kilner jars covered with mesh lids and replicated five times. After seven days of feeding, mating, and oviposition, the old weevils were removed. Kilner jars were observed daily until the emergence of the teneral adult weevils and they were removed from the cultures as they emerge and sexed using the method described by Halstead [11]. This insect culture was maintained and used as source of $S$. linearis throughout the course of the study.

Samples (200 g) of tamarind seeds were weighed and kept in Kilner jars. Since large numbers of weevils were required and daily emergence was not enough to provide them, two hundred 2-week-old unsexed adult tamarind weevils from the laboratory culture were introduced into each of the five Kilner jars (A. A. Omoloye pers. comm.). They were allowed to remain for 4 days to feed, mate, and oviposit on the seeds and thereafter removed. A daily dissection of the infested seeds started a day following the removal of the insects in order to study larval development of the weevil. The cylindrical cavities dug in infested seeds by the weevils were keenly observed to locate egg plug. Twenty pieces of infested seeds were dissected daily in a petri dish for vertex measurement using binocular microscope fitted with a micrometer eyepiece and digital microscope. The stages of larval development were determined using the measurement of vertex width [12] and duration (days) from the beginning of oviposition until the time of each dissection; these procedures continued daily until adults emerged. Using vertex width measurement for larval instars, $t$-test for conformity to Dyar's rule was conducted [13]. Data were collected on developmental time and width of head capsule on different instars removed from the grains dissected daily for tamarind weevil species.

Data on head capsule widths of larval instars were analyzed using analysis of variance (ANOVA) and means when significant were separated using Tukey's Honestly
TABLE 2: Developmental period (days) and body measurements $(\mathrm{mm}) \pm \mathrm{SE}$ of the life stages of $S$. linearis.

\begin{tabular}{lccc}
\hline Stages & $\begin{array}{c}\text { Body length } \\
(\mathrm{mm} \pm \mathrm{SE})\end{array}$ & $\begin{array}{c}\text { Body width } \\
(\mathrm{mm} \pm \mathrm{SE})\end{array}$ & $\begin{array}{c}\text { Developmental } \\
\text { period (days) }\end{array}$ \\
\hline Egg & 0.61 & 0.3 & 3 \\
Instar 1 & $0.57 \pm 0.01 \mathrm{c}$ & $0.33 \pm 0.01 \mathrm{~d}$ & 3 \\
Instar 2 & $0.61 \pm 0.01 \mathrm{c}$ & $0.48 \pm 0.02 \mathrm{c}$ & 2 \\
Instar 3 & $0.84 \pm 0.02 \mathrm{~b}$ & $0.69 \pm 0.01 \mathrm{~b}$ & 2 \\
Instar 4 & $1.71 \pm 0.05 \mathrm{a}$ & $1.09 \pm 0.02 \mathrm{a}$ & $7-9$ \\
Pupa & $3.86 \pm 0.03$ & $1.46 \pm 0.01$ & 8 \\
Adult male & $4.10 \pm 0.06$ & $1.18 \pm 0.00$ & \\
Adult female & $4.25 \pm 0.02$ & $1.19 \pm 0.02$ & \\
\hline
\end{tabular}

Means followed by the same letter in a column between the larval instars are not significantly different at $5 \%$ level of probability as determined by Tukey's Honestly Significant Difference (HSD) test.

Significant Difference (HSD) test at 5\% level of probability. The relationship between the head capsule widths of all larval instars and duration of each instars was subjected to regression analysis, and the regression coefficient $\left(R^{2}\right)$ was determined.

\section{Results}

3.1. Life History and Description of the Life Stages of S. linearis. Mating in S. linearis began few days after emergence, and the female started laying egg a week after mating. Oviposition period ranged between 77 and 98 days with an average of 86.8 days. Total average number of eggs laid per female was 165 with a range of 132-189 eggs (Table 1). The egg incubation period was 3.17 days with a range of 3-4 days. Average longevity of adult $S$. linearis was 108.5 days which ranged between 91 and 126 days. The adult $S$. linearis bores into the tamarind seed using its strong rostrum. It excavates a cylindrical hole in the seed and lays eggs in it (range of 9-34 eggs), the eggs were grouped together, and the female stayed in the cavity until it laid the last egg but it moved away when disturbed. Female tamarind weevil bores a single cavity at a time for 2-3 days and lays 9-34 eggs in it, and a range of 27 larvae hatched later. The egg of S. linearis is oval in shape, whitish, and somehow rounded at the bottom. It is glued to the tamarind seed in the cavity, and measured $0.61 \mathrm{~mm}$ in length and $0.3 \mathrm{~mm}$ in width. The eggs hatched after three days, the newly hatched larva is apodous, fleshly grub which is pearly/creamy white, and the head is light brown. The means of head capsule of the tamarind weevil larval instars increased from the first instar to the fourth instar and were significantly different $(P<0.05)$ from one another (Table 2$)$. The mean body length of first larval instar was $0.57 \mathrm{~mm}$ with a range of $0.50-0.61 \mathrm{~mm}$ and the body width was $0.33 \mathrm{~mm}$ with a range of $0.27-0.37 \mathrm{~mm}$, and the first instar lasted 3 days. The second instar larva is creamy white, wider, and longer than the first instar, it measured between 0.52 and $0.69 \mathrm{~mm}$ with an average of $0.61 \mathrm{~mm}$ in length and between 0.31 and $0.57 \mathrm{~mm}$ with an average of $0.48 \mathrm{~mm}$ in width, and the mean developmental period was 2 days. The average body length of the third instar 
TABLE 3: Head capsule \pm (SE) measurement of larval instars of S. linearis.

\begin{tabular}{|c|c|c|c|c|c|c|}
\hline Instar & $N$ & Range (mm) & $\begin{array}{l}\text { Mean of head capsule } \\
\text { width }(\mathrm{mm})\end{array}$ & $\begin{array}{l}\text { Growth } \\
\text { ratio }\end{array}$ & $\begin{array}{l}\text { Stadium } \\
\text { of instars }\end{array}$ & $\begin{array}{c}\text { Accumulated } \\
\text { days of } \\
\text { development }\end{array}$ \\
\hline I & 22 & $0.21-0.27$ & $0.24 \pm 0.00 c$ & & 3 & \\
\hline II & 24 & $0.25-0.37$ & $0.29 \pm 0.01 c$ & 1.21 & 2 & 5 \\
\hline III & 22 & $0.30-0.48$ & $0.39 \pm 0.01 b$ & 1.34 & 2 & 7 \\
\hline IV & 70 & $0.39-0.69$ & $0.56 \pm 0.01 \mathrm{a}$ & 1.44 & $7-9$ & 16 \\
\hline \multicolumn{4}{|c|}{ Mean growth ratio } & 1.33 & & \\
\hline
\end{tabular}

Means followed by different letters along the column are significantly different from each other $(P=0.05)$ (Tukey's HSD test).

Growth ratio = the mean head capsule width of a succeeding instar divided by the mean head capsule width of a preceding instar.

was $0.84 \mathrm{~mm}$ and ranged between 0.73 and $0.92 \mathrm{~mm}$ while the average body width was $0.69 \mathrm{~mm}$ and ranged between 0.56 and $0.79 \mathrm{~mm}$. The mean developmental period was 2 days. The fourth instar is wider and longer than third instar larva, it measured between 0.90 and $2.51 \mathrm{~mm}$ in length with an average of $1.71 \mathrm{~mm}$ and between 0.78 and $1.20 \mathrm{~mm}$ in width with an average of $1.09 \mathrm{~mm}$, and the mean developmental period was 9 days.

The fourth instar larva transformed into prepupa which molts into pupa few hours later. It appeared white, with oval head with slender and elongated beak. When observed closely, the pupa is exarate (legs and appendages separately encased), and the wings and legs were not glued to the body. It measured between 2.56 and $4.15 \mathrm{~mm}$ with an average of $3.86 \mathrm{~mm}$ in length and between 1.30 and $1.61 \mathrm{~mm}$ with an average of $1.46 \mathrm{~mm}$ in width, and it takes an average of 8 days for pupa to develop into an adult. The newly formed adult (pharate), light reddish in colour, does not leave the tamarind seed immediately but waits inside the seed for 4-7 days (average of 6 days) until its body wall hardened and is active; the colour then changes to dark brown. After its emergence, the seed becomes empty with frass (mass of powder) observed. The tamarind weevil completed its life cycle in 25-33 days.

3.2. Growth in Larvae of S. linearis. On the basis of the daily mean widths of the head capsule measurements in the study, four larval instars were identified (Figure 1) and the duration of larval instars was 16 days (Table 2). The head capsule width increased with successive instars. The growth rate of the instars varied between 1.21 and 1.44 with a mean of 1.33 for this insect species (Table 3). Table 4 shows the conformity of the head capsule measurement to Dyar's rule, and, based on a $t$-test for the differences between the observed average head capsule width and the calculated average $(d)$, a $t$-value greater than 3.182 was needed to depict a significant difference between the observed and the calculated averages. However, a $t$-value of 0.47 was obtained (Table 4) indicating no significant difference and indicating that the data conformed to Dyar's rule. The relationship between the measurements of the head capsule and accumulated days of larval development was a regular one. Linear regression line and the correlation coefficient $(r=0.94 ; P<0.05)$ showed significant relationship between larval instars and

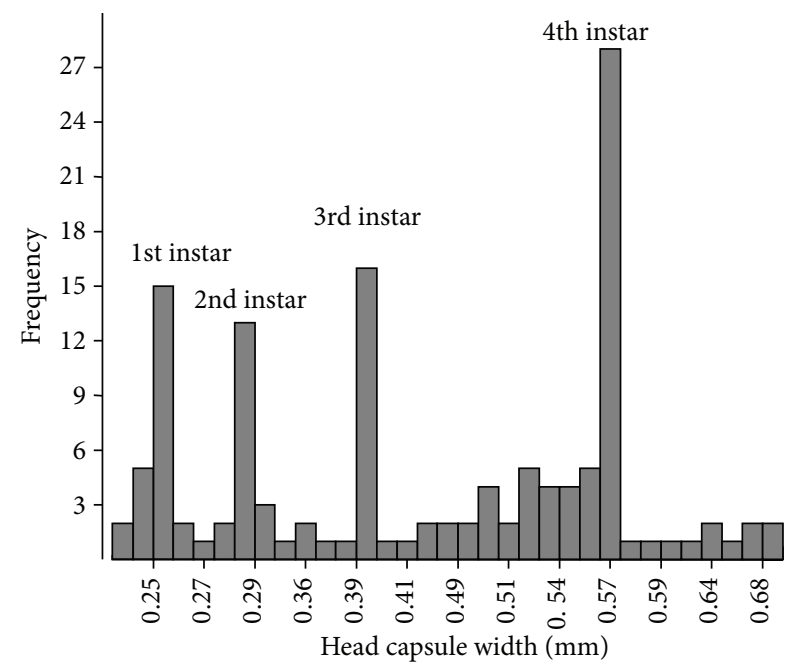

FIGURE 1: Frequency distribution of the head capsule width of larval instars of S. linearis.

TABLE 4: The head capsule width for larval instars of S. linearis and test for conformity to Dyar's rule.

\begin{tabular}{lcccc}
\hline Instar & $\begin{array}{c}\text { Observed } \\
\text { average }\end{array}$ & $\begin{array}{c}\text { Growth } \\
\text { ratio }\end{array}$ & $\begin{array}{c}\text { Calculated } \\
\text { average }\end{array}$ & Differences \\
\hline I & 0.24 & & 0.32 & -0.03 \\
II & 0.29 & 1.21 & 0.39 & 0.00 \\
III & 0.39 & 1.34 & 0.52 & 0.04 \\
IV & 0.56 & 1.44 &
\end{tabular}

Note. Calculated average $=$ observed mean head width of a preceding instar multiplied by the mean growth ratio.

Average difference $(d)=0.0033$.

Standard deviation of the differences $=0.021$.

$T \mathrm{cal}=d / s / n . T \mathrm{cal}=0.47 ; T \mathrm{tab}=3.182$.

Reject Ho if $T$ cal $>T$ tab.

Decision: do not reject Ho, growth ratio conforms to Dyar's rule.

head capsule width (Figure 2). A straight line generated in the figure also indicated conformity to Dyar's rule.

\section{Discussion}

The study on the developmental biology of Sitophilus linearis on tamarind has not been pursued extensively in this area 


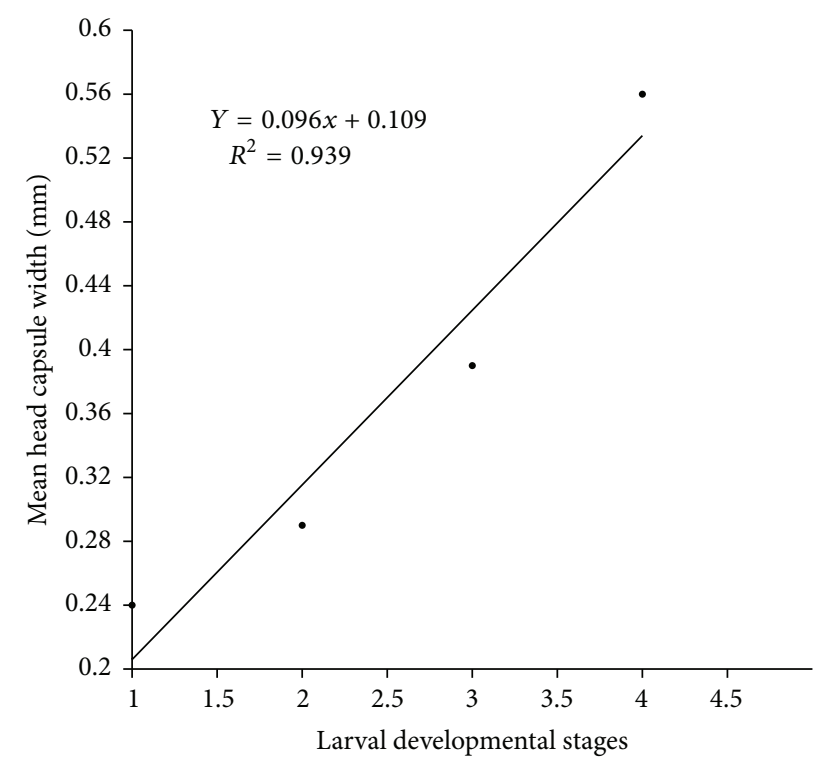

Figure 2: Relationship between head capsule width and larval developmental stages of $S$. linearis.

where the study was carried out. The mean incubation period of $S$. linearis eggs in this study under laboratory condition was 3.2 days which ranged between 3 and 4 days. This was in agreement with the earlier report that the incubation period of $S$. linearis is 3 days [7]. A similar incubation period of 3-4 days was reported for Sitophilus rugicollis [14], a congeneric species of Sitophilus linearis and other Sitophilus species, whereas an incubation period of 5.1 days was observed with $S$. oryzae cultured on maize grains [15]. The little variation observed on the incubation period could be a result of prevailing environmental condition, especially temperature recorded in different locations. Mated females of S. linearis laid an average of 165 eggs (range of 132-189 eggs) over a period of 86.8 days with total developmental period (egg to adult) of 25-33 days. Similarly, a developmental period of 22-26 days was recorded on the same insect [7]; also sal seed weevil, S. rugicollis, had a total developmental period of 22-34 days [14]. The adult longevity ranged between 91 and 126 days (average of 108.5 days), and the oviposition period ranged between 77 and 98 days (average of 86.8 days). These findings were similar to earlier report where the oviposition period of $S$. linearis was 84 days, and total number of eggs laid ranged between 126 and 165 eggs [7]. The moderately high number of eggs (132-189), shorter larval developmental period (16 days), and long oviposition period (77-98 days) would enhance faster population growth, multivoltinism, and sustainability of $S$. linearis throughout the year. The larval head capsule width when measured with successive instars and the frequency distribution of the width of head capsules of the larvae showed that there are four larval instars. The growth ratio varied from 1.21 to 1.44 with a mean growth ratio of 1.33 , which tends to be very close to growth ratio obtained for other curculionids, black soybean weevil, Rhyssomatus subtilis, 1.32-1.50 with a mean growth ratio of 1.45 [16], Guava weevil, Conotrachelus psidii, $1.34-1.42$ with a mean growth ratio of 1.37 [17]. The significance of this growth ratio is that growth progresses at a constant rate in each molt. The regular relationship of the larval vertex and the significant regression coefficient $\left(R^{2}=0.939\right)$ clearly confirmed that no stadium was overlooked during the study of developmental biology. The total larval developmental period was 14-16 days and with a pupa developmental period of 8 days. This agrees partly with earlier report where $S$. linearis has larval developmental period of 14-15 days and pupal period of 7-8 days [7]. So the life cycle of S. linearis consists of egg, four larval instars, pupa, and adult.

\section{Conflict of Interests}

The authors declare that there is no conflict of interests with any commercial identities mentioned in this paper.

\section{Authors' Contribution}

All authors reviewed and approved the final paper.

\section{References}

[1] E. L. Little and F. W. Wadsworth, Common Trees of Puerto Rico and the Virgin Islands, vol. 249 of Agriculture Handbook, U.S. Department of Agriculture, Washington, DC, USA, 1964.

[2] J. M. Dalziel, The Useful Plants of West Tropical Africa, Crown Agents for Oversea Governments and Administrations, London, UK, 1937.

[3] National Academy of Sciences, Tropical Legumes: Resources for the Future, National Academy of Sciences, Washington, DC, USA, 1979.

[4] R. M. Rama, Flowering Plants of Travancore, Bishen Singh Mahendra Pal Singh, Dehradun, India, 1975.

[5] A. P. Benthal, The Trees of Calcutta and Its Neighborhood, Thacker Spink \& Co., Calcutta, India, 1933.

[6] D. K. Butani, "Insect pests of tamarind and their control," Pesticides, vol. 12, no. 11, pp. 34-41, 1978.

[7] R. T. Cotton, Tamarind Pod Borer, Sitophilus linearis (Herbst) Stored-Product Insect Investigations, United States Department of Agriculture, Bureau of Entomology, 1920.

[8] R. Plarre, "An attempt to reconstruct the natural and cultural history of the granary weevil, Sitophilus granarius (Coleoptera: Curculionidae)," European Journal of Entomology, vol. 107, no. 1, pp. 1-11, 2010.

[9] J. A. Ojo and A. A. Omoloye, "Rearing the maize weevil, Sitophilus zeamais, on an artificial maize-cassava diet," Journal of Insect Science, vol. 12, article 69, 9 pages, 2012.

[10] C. O. Adedire, "Biology, ecology and control of insect pests of stored cereal grains," in Pests of Stored Cereals and Pulses in Nigeria: Biology, Ecology and Control, T. I. Ofuya and N. E. S. Lale, Eds., Dave Collins Publications, 2001.

[11] D. G. H. Halstead, "External sex differences in stored product coleopteran," Bulletin of Entomological Research, vol. 54, no. 1, pp. 119-134, 1963.

[12] S. Sharifi and R. B. Mills, "Radiographic studies of Sitophilus zeamais Mots. in wheat kernels," Journal of Stored Products Research, vol. 7, no. 3, pp. 195-206, 1971.

[13] J. B. Odebiyi, "Studies on the biology of the cowpea pod-borer, Maruca testulalis in Kenya-I. Determination of the larval 
instars," International Journal of Tropical Insect Science, vol. 1, no. 4, pp. 339-341, 1981.

[14] V. Choubey, R. Bhandari, and N. Kulkarni, "Life history and morphology of seed weevil, Sitophilus rugicollis casey (Coleoptera: Curculionidae) infesting sal seeds in Madhya Pradesh," Journal of Entomological Research, vol. 37, no. 3, pp. 259-267, 2013.

[15] K. C. Narayana Swany, G. P. Mutthuraju, E. Jagadeesh, and G. T. Thirumalaraju, "Biology of Sitophilus oryzae (L.) (Coleoptera: Curculionidae) on stored maize grains," Current Biotica, vol. 8, no. 1, pp. 76-81, 2014.

[16] L. E. Cazado, G. A. Van Nieuwenhove, C. W. O’Brien, G. A. Gastaminza, and M. G. Murúa, "Determination of number of instars of Rhyssomatus subtilis (Coleoptera: Curculionidae) based on head capsule widths," Florida Entomologist, vol. 97, no. 2, pp. 639-643, 2014.

[17] O. E. Bailez, A. M. Viana-Bailez, J. O. G. De Lima, and D. D. O. Moreira, "Life-history of the guava weevil, Conotrachelus psidii Marshall (Coleoptera: Curculionidae), under laboratory conditions," Neotropical Entomology, vol. 32, no. 2, pp. 203-207, 2003. 

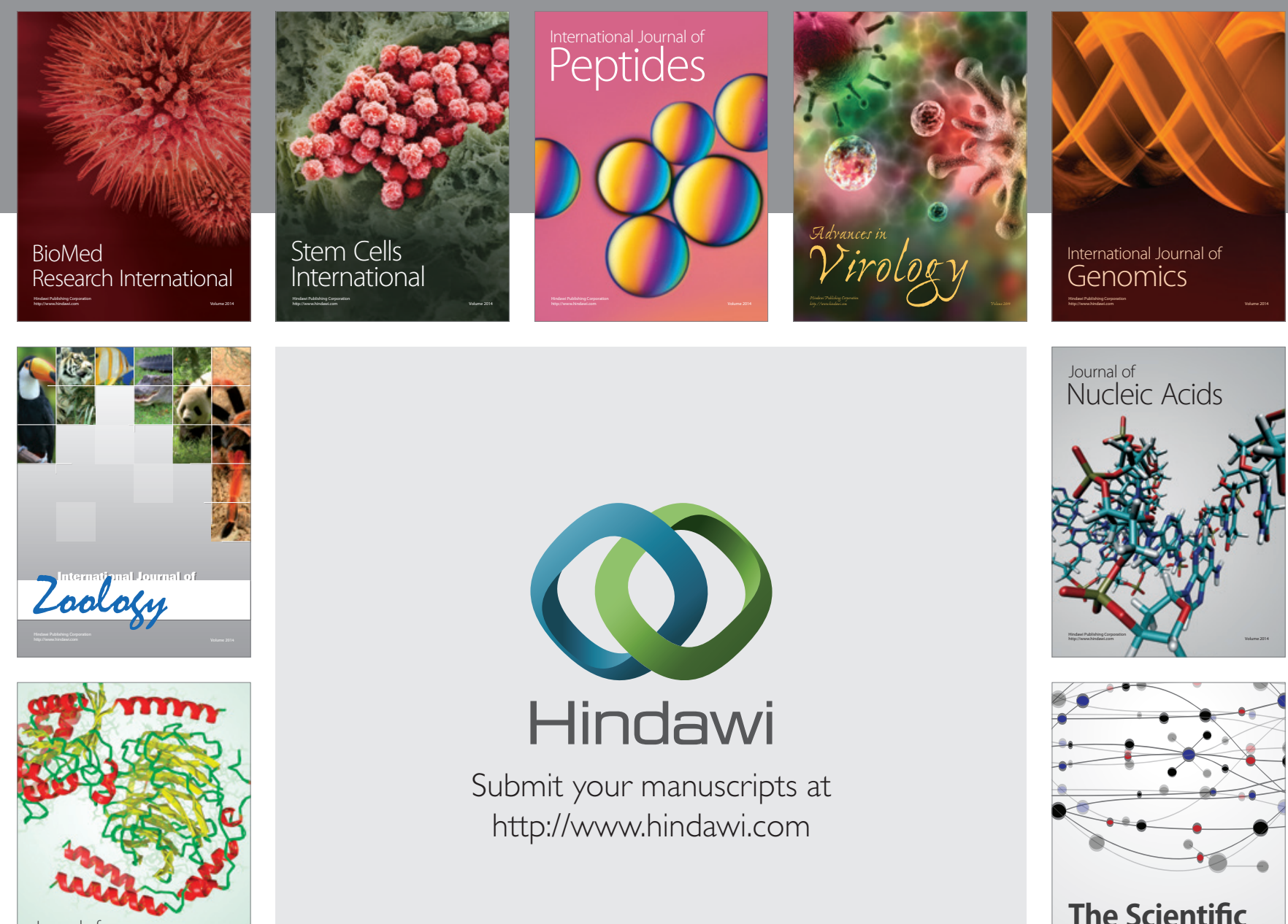

Submit your manuscripts at

http://www.hindawi.com

Journal of
Signal Transduction
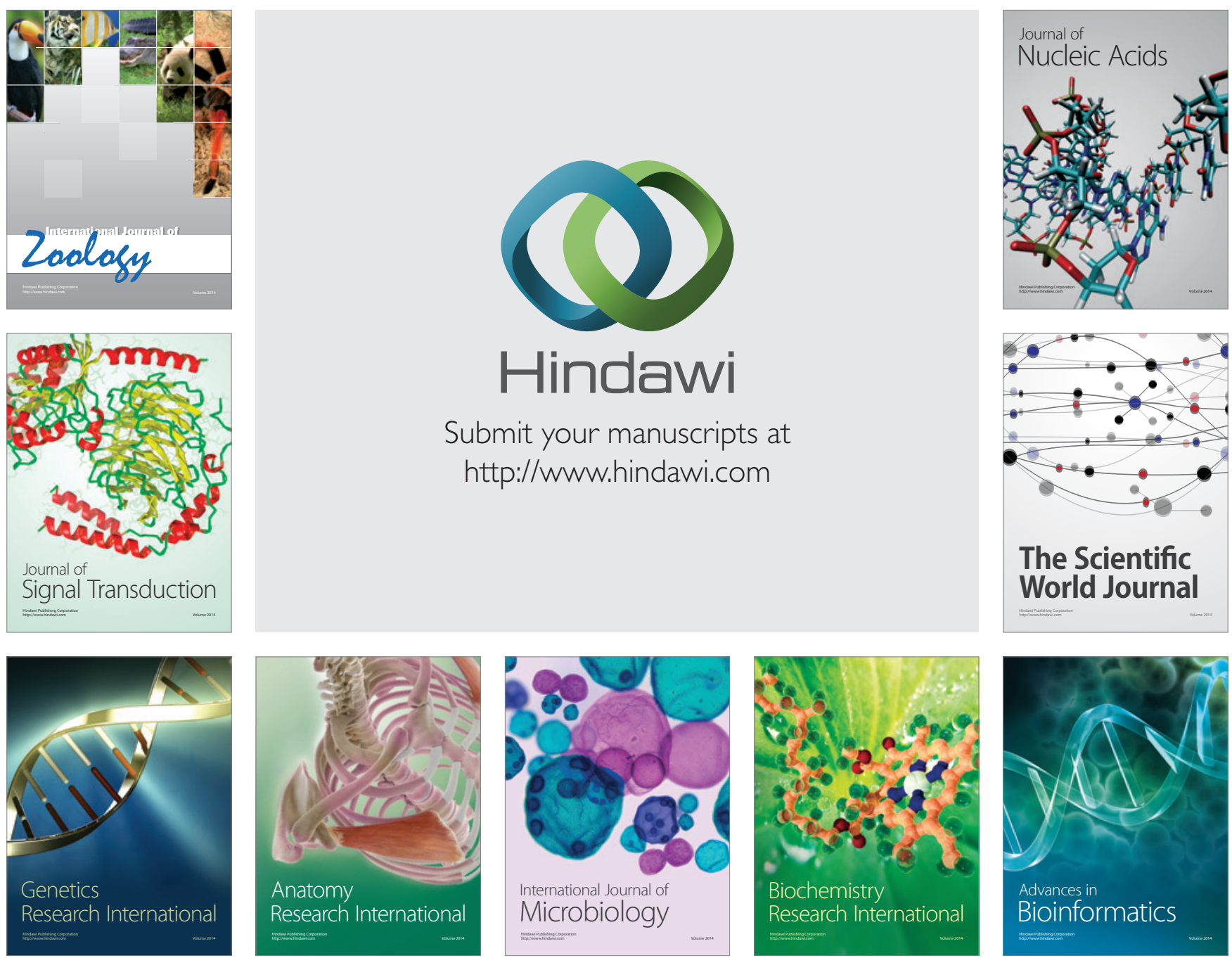

The Scientific World Journal
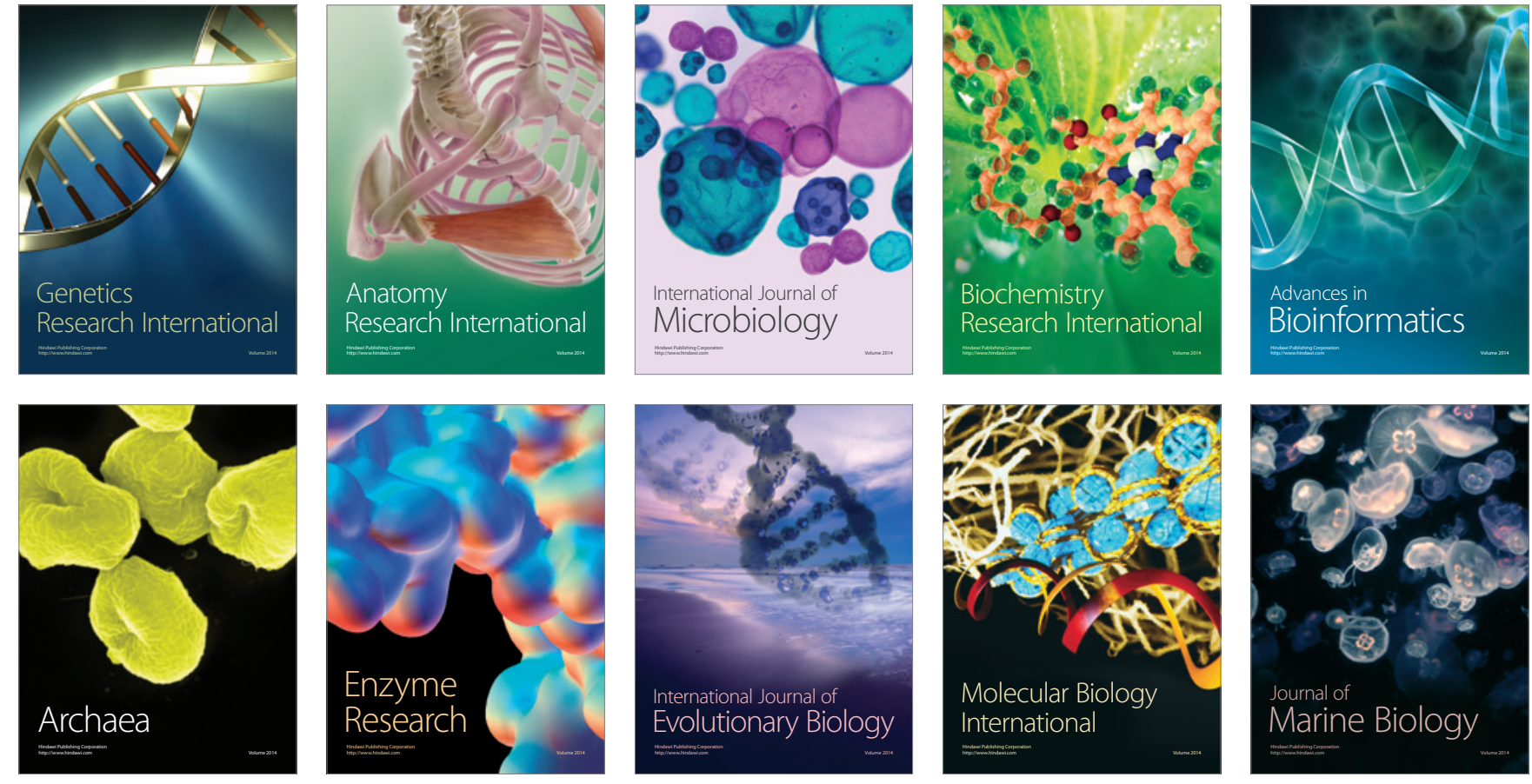